\title{
PARÂMETROS PARA UMA ABORDAGEM PROCESSUAL DO ENSINO DE PROJETO EM DESIGN.
}

\author{
Autores \\ Dra. Anna Lúcia dos Santos Vieira e Silva \\ Universidade Federal do Ceará \\ annalucialilu@gmail.com \\ Dra. Claudia Teixeira Marinho \\ Universidade Federal do Ceará \\ marinhoclufc@gmail.com \\ Dra. Alexia Carvalho Brasil \\ Universidade Federal do Ceará \\ Alexia.br@mac.com \\ Breno Ehrich Colares \\ Universidade Federal do Ceará \\ brenoehrich@gmail.com
}

\begin{abstract}
Resumo: Neste artigo são abordadas metodologias para a análise das produções realizadas nas disciplinas de projeto do terceiro ao sexto semestre do curso de design. Os estudos sobre o processo são acionados para compreender as ações projetuais, realizadas no cotidiano das aulas pelos professores e alunos das disciplinas descritas, utilizando seus registros como documentos de análise. O objetivo é identificar e definir estratégias que contribuam para a construção de ações pedagógicas, de modo a dar continuidade à realização efetiva de uma pesquisa em andamento, elaborada pelo no "Laboratório de Experimetação da Representação de Projeto" com base nas perspectivas oferecidas pelas metodologias da Crítica Genética e da Pesquisa-Ação. Os trabalhos integrados das disciplinas de projeto de produto e projeto gráfico são o objeto da pesquisa e se apropriam das estruturas teóricas e físicas do LabRep, como espaço de experimentação das formas de representação, com foco nas etapas de concepção, desenvolvimento e apresentação do projeto.
\end{abstract}

Palavras-chave: ensino, projeto, metodologia.

Abstract: This paper tackles methodology for the analysis of the works presented by students of the project classes from the third through sixth semesters. Studies regarding process are done to comprehend projectual acts, performed daily in classes by both students and educators of such classes, using drafts and annotations as 
documents for analysis. The goal is to identify and define strategies capable of improving the elaboration of pedagogic actions, thus allowing the existing research in "Laboratório de Experimetação da Representação de Projeto" to continue in an effective way, with foundations in the perspectives offered by Genetic Criticism and action research. The joint works between the Graphic Project and Product Project classes are the object of the study and they make use of the physical and theoretical structures of "LabRep", as an environment for the experimentation in ways for representation, with a focus on the stages of conception, development and presentation of a project.

Keywords: education, project, methodology.

\section{INTRODUÇÃO}

O LabRep - Laboratório de experimentação da Representação do Projeto - é um projeto de pesquisa que tem como objetivo criar um espaço de reflexão e prática sobre o ensino de projeto a partir do foco da representação. Está direcionado às atividades de ensino das disciplinas em questão, para a obtenção de uma sistemática que traduza e desenvolva o Projeto Político Pedagógico (PPP) do curso. Ele visa a adequação à demanda local e resulta em uma proposta de formação generalista que abrange as áreas de projeto de produto e projeto gráfico.

As áreas de saber que compõem o curso, chamadas Unidades Curriculares, são: Projeto, Tecnologia e Humanística, enquanto a unidade de projeto abrange percepção e representação nas áreas de projeto gráfico e de produto. As disciplinas de projeto tem por objetivo estimular o aluno a desenvolver a percepção e a linguagem gráfica, assim como os meios de sua expressão criativa. Tem como fundamento o compromisso de sedimentar o pensamento do design no curso que iniciou em 2012, considerando suas especificidades como área de conhecimento e a produção de projetos integrados durante o desenvolvimento das disciplinas do ciclo profissionalizante de Projeto Gráfico (PG) e Projeto de Produto (PP).

O projeto está organizado em três Núcleos de Investigação, um Laboratórios de Experimentação e um Grupo de Pesquisa. Os núcleos de investigação são responsáveis pelos tópicos de ordem teórica do projeto, o laboratório cumpre a função de sedimentação dos vínculos entre as pesquisas envolvidas no projeto, sendo no Grupo de Pesquisa são traçados os princípios que fundamentam o desenvolvimento, avaliação e catalogação de estratégias voltadas para o ensino do projeto.

Desta forma o laboratório se propõe a congregar as atividades sintetizadoras de projeto em suas diferentes modalidades. A não separação das disciplinas de representação e de projeto favorece a proposta de pensar o desenho no seu sentido mais amplo, como um dispositivo criativo. Isto somado a prática de ensino ao modo que descreve Shön (2010), como reflexão na ação ou como uma postura ativa no aprendizado, torna o atelier de ensino um ambiente distinto das salas de aula convencionais, e digno de estudo. Isso significa que, embora haja uma maior concentração de disciplinas que tratam especificamente representação no primeiro ano do curso, entende-se que os problemas relativos ao domínio das ferramentas de representação não se encerram no ciclo de fundamentação. Ao contrário, o domínio representação, acompanha as disciplinas de projeto que estão presentes em todo o curso. Durante o ano de fundamentação, com as disciplinas Projeto 1 e Projeto 2; nos 
quatro semestres de profissionalização com as sequências de Projeto Gráfico 1, 2, 3, 4 e Projeto de Produto 1, 2, 3, 4 (trabalhos integrados); e no último ano com a atividade Trabalho de Curso do ciclo de conclusão.

Os trabalhos integrados, que são o objeto da pesquisa, se apropriam das estruturas teóricas e físicas do LabRep, como espaço de experimentação das formas de representação, com foco nas etapas de concepção, desenvolvimento e apresentação do projeto. Cada uma destas etapas está estruturada em torno de quatro eixos temáticos, de fundamentação histórica, relacionados à modelos teóricos que marcaram diferentes identidades do projeto, que são: objeto, identidade, interface, e o discurso. Esses tópicos estão fundamentados na abordagem feita por Krippendorf (2001) sobre os paradigmas do projeto de design a partir da revolução industrial.

Resultados parciais desta pesquisa já foram apresentados em trabalhos anteriores, ocasião em que discutimos sobre uma metodologia de projeto centrada nas lógicas das ações. Neste texto, são abordadas metodologias de análise das produções realizadas nas disciplinas de projeto. Os estudos sobre o processo são acionados para compreender as ações de projetos, realizadas no cotidiano das aulas, pelos professores e alunos das disciplinas descritas, a partir dos registros, que são documentos de análise. O objetivo é identificar e definir estratégias que contribuam para a construção de ações pedagógicas de modo a dar continuidade à realização efetiva da pesquisa em andamento, com base nas perspectivas oferecidas pelas metodologias da Crítica Genética e da Pesquisa-Ação.

\section{DESENVOLVIMENTO}

As ações que implicam uma atividade projetual em Design podem ser analisadas através de um olhar semiótico, como proposto pela Crítica Genética, que possibilita compreender a envergadura da atuação do estudante em momentos específicos das disciplinas de Projeto no contexto do curso.

No caso deste trabalho, a Critica Genética é empregada como ferramenta para abordar a análise dos procedimentos projetuais - e sua natureza complexa - tendo em vista uma vocação do design contemporâneo de promover reconhecimento (por vezes consenso) entre diferentes discursos e subjetividades; o que lhe facultaria uma natureza trans e interdisciplinar. Busca-se, portanto, a partir desta metodologia, uma compreensão das representações obtidas no desenvolvimento das disciplinas de Projeto e suas implicações, a partir dos resultados materiais, registros concretos nos quais o processo, ou parte dele, esteja manifestado.

A Crítica Genética é uma área de estudo que surgiu na França em 1968, a partir das investigações de manuscritos literários de escritores como Flaubert. Nas duas últimas décadas, por iniciativa do CECG - PUC|SP - começaram a surgir pesquisadores interessados em estudar outras áreas; como as artes, a fotografia, a publicidade, dança, arquitetura, cinema, bem como aplicar os conhecimentos reunidos a partir destas pesquisas em investigações voltadas para compreender as dinâmicas produtivas em áreas de conhecimento marcadas pela interdisciplinaridade, como é o caso do design. O manuscrito passou a ser denominado documento de processo e o que era restrito à literatura alcançou as outras linguagens (Salles, 1998). Quando analisamos um documento de processo, estamos face a face com um registro do tempo, do ato, um índice. 
As estratégias de pesquisa oferecidas pela Crítica de Processo, como proposto por Salles (1994) se dirigem a uma readequação da metodologia da Critica Genética para abordar outras áreas de conhecimento que não somente a literatura. Mostram-se como uma ferramenta eficaz para pensar os processos do projeto, cotejando as transformações que ocorrem em seu desenvolvimento, por meio de representações diversas.

O objetivo da Crítica de Processo é oferecer uma nova possibilidade de abordagem das "produções" que tem a criação como mote, em busca de fundamentos para descrever as diferentes lógicas de processo - como ocorre na arte, na fotografia no cinema, na arquitetura e no design. Trata-se de uma estratégia de investigação que possibilita um tratamento metodológico das informações dos processos criativos e produtivos.

A metodologia oferecida pela Crítica Genética, com fundamentos na semiótica peirceana, investe em uma noção ampliada de comunicação, para abordar os processos criativos em diferentes áreas, ao mesmo tempo em que mostra-se como uma ferramenta estratégica para pensar as dinâmicas projetuais; na medida em que possibilita compreender, a partir dos estudos sobre as manifestações representadas, os sistemas de informação e as dinâmicas comunicativas que estruturam "os discursos" que envolvem o projeto.

A pesquisa aborda, no entanto, duas linhas metodológicas. A primeira diz respeito a metodologia aplicada aos alunos e se desenvolve a partir da proposta de trabalho solicitada. A segunda abrange a classificação e análise das informações a partir dos resultados obtidos.

Atualmente algumas metodologias tratam do estudo de situações em processo, abertas para transformações por serem elas próprias um estudo inserido no desenvolvimento da investigação, especialmente quando esta implica em abordagens interdisciplinares e complexas. Especificamente na área educacional, a pesquisa-ação se volta a estratégias de pesquisa que se direcionam ao aprimoramento do ensino em decorrência dos resultados e do aprendizado dos alunos. A investigação-ação é aplicada em processos cíclicos que envolvem a qualificação de uma prática a partir de ações e investigações sobre sua realidade intrínseca. Quatro etapas fundamentam a investigação-ação: o planejamento de uma qualificação em uma situação vigente; a ação para implementar a melhora projetada; monitorar, descrever os efeitos da ação; e avaliar os resultados, para retomar a etapa inicial, promovendo assim um continuum evolutivo e adaptativo. As duas primeiras etapas são ativas e as duas seguintes são investigativas.

"Planeja-se, implementa- se, descreve-se e avalia-se uma mudança para a melhora de sua prática, aprendendo mais, no correr do processo, tanto a respeito da prática quanto da própria investigação. A maioria dos processos de melhora segue o mesmo ciclo. A solução de problemas, por exemplo, começa com a identificação do problema, o planejamento de uma solução, sua imple- mentação, seu monitoramento e a avaliação de sua eficácia." (TRIPP, 2005, p. 444-445)

Na definição de Donald Tripp (2005, p. 447) a pesquisa-ação "é uma forma de investigação-ação que utiliza técnicas de pesquisa consagradas para informar a ação que se decide tomar para melhorar a prática". O autor acrescenta a importância de sua integração no âmbito da pesquisa acadêmica, inclusive por seguir os mesmos critérios. Desta forma, se caracteriza tanto pela prática cotidiana quanto pela pesquisa 
científica. Na pesquisa-ação, a metodologia serve a prática e esta alimenta a investigação, que se volta novamente à prática de forma documentada, intervencionista, reflexiva e compreendida.

Ainda que a metodologia seja aberta e integrada ao processo, existem necessidades sistemáticas de documentação, análise e redirecionamento dos resultados para que a continuidade do aperfeiçoamento do processo possa se dar de maneira efetiva. Como anteriormente descrito, a Crítica Genética é um método aliado à análise dos documentos, um olhar semiótico sobre as representações em processo dos alunos.

No LabRep, o procedimento de documentação e as estratégias para organizar os dados documentados estão incluídos como elementos de investigação, como observa-se a seguir.

\subsection{Descrição do corpus da pesquisa}

Tendo em vista a relativização dos modelos de projetos já descritos e a experimentação para a proposição de novos métodos de projeto, optamos por definir um recorte do contexto das informações, descrito pelas ações e discursos dos professores e alunos, para privilegiar uma abordagem analítica dos caminhos trilhados pelos agentes envolvidos nos processos de ensino-aprendizado - a partir de uma análise dos documentos gerados - para propor ações pedagógicas.

Para a definição do corpus da pesquisa, foram consideradas os seguintes fatores: 1-) Metodologia : a integração dos métodos da crítica de processo (Salles, 2010) e pesquisa ação (Tripp, 2005). 2-) Resultados esperados: a qualificação das informações, geradas durante o encaminhamento das disciplinas, de modo a integrálas na rede de significações que constituem as dimensões discursivas do design. (Krippendorf, 2001).

O contexto de abordagem do LabRep implica os Trabalhos Integrados, que envolvem as disciplinas de Projeto de Produto e Projeto Gráfico, realizados nos 3으, 4으, , 50 e 6 o períodos do curso. Como amostragem tomamos o projeto desenvolvido no 3 은 semestre , cujo objetivo é a capacitação para o desenvolvimento de documentos de projeto voltados para a produção industrial.

O problema apresentado aos alunos foi o desenvolvimento de um expositor de trabalho acadêmico; uma releitura da proposta "estrutura expositora ", de Bruno Munari (1998).

\subsection{Detalhamento da amostragem e parâmetros encontrados}




\section{Projeto de produto 1}

\section{Expositor}

O projeto tem como princípio a "estrutura expositora " de Bruno Munari (c.f. Munari, 1998. Das coisas nascem coisas. p 246, 256). A primeira edição italiana do livro foi publicada no inicio dos anos 80 , o projeto apresentado deve ter sido executado na década de 70. Tendo em vista a atualização da demanda, certamente haverá possibilidade de investigação de novas soluções para o problema. Podem ser considerados, por exemplo, outros materiais bem como as possibilidades de impressão e fabricação digital para realização dos protótipos.

\section{PROBLEMA:}

Projetar um suporte para exposição de trabalhos acadêmicos.

Desmontável e fácil de montar e auto-portante.

CONTEXTO:

Todo ano são montadas estruturas para exposições diversas de caráter acadêmico. Feiras das profissões, encontros universitários, semanas de cursos e centros. Nas exposições apresentam-se principalmente pôsteres que se conformam pelas limitações de impressão e ergonomia em formatos de $90 \times 120 \mathrm{~cm}$. Ocorre também a demanda ocasional das escolas por visita e exposição dos cursos. O problema pode ser tomado como uma oportunidade de mostrar o curso de Design a partir do design de uma solução de expositor. Para ter efeito explicativo e retórico, o expositor deve traduzir conceitos basilares de design em sua solução. Além disso, deverá possibilitar um ganho de funcionalidade, versatilidade e simplicidade (pelo menos) em relação aos expositores convencionais.

\section{INOVAÇÃO}

É esperado que cada equipe apresente, diante deste contexto dado, inovações no entendimento do problema, bem como nas soluções apontadas.

\section{Etapas de investigação}

I. Forma proporção e modulação

reduzir a uma variação mínima de peças combináveis para um expositor.

Modulação e variação: permitir diferentes arranjos para comportar tamanhos diferentes de painéis, bem como painéis para projeção e suporte para objetos. ( protótipos, maquetas, modelos)

Pensar em termos de planos (opacos ou vazados), linhas e rótulas.

II. Materiais e processos

1. Investigar possibilidades de materiais que podem ser empregados. Suas vantagens de flexibilidade, variedade, custo, leveza, resistência, etc.

2. Investigar que materiais são usados em soluções já existentes.

3. Inferir quais materiais são mais adequados quanto a aparência e forma.

4. Conhecer a padronização dos materiais disponíveis e adequar uso e otimização de corte. Indicar material e processo, caso haja necessidade de usinarem de alguma peça.

\section{Sistema}

1. Como desmontar condicionar, armar, guardar, embalar, transportar?

2. Como instruir sobre o uso? Quantas peças? Quantas pessoas precisa para montar? É necessário alguma ferramenta?

3. Como comunicar? Pensar no sistema de exposição, curadoria, quantas 
peças gráficas e objetos, tipo de peças, arranjos e montagem; sinalização da exposição.

4. Investigar e padronizar tipos de montagem. Por exemplo: montagem mínima, montagem regular ou ideal, mega montagens.

5. Investigar sobre as necessidades dos eventos, não previstas nesse programa. Entrevistar montadoras e observar montagens. Quais problemas apontados? Essa é a melhor maneira de fazer uma exposição? O que é ganho de memória, o que é hábito sem propósito?

\section{Metodologia:}

As etapas I, II, e III são simultâneas ou sucessivas? Existem mais etapas ou subetapas?

De acordo com as metodologias estudadas qual o roteiro proposto pela equipe.

Explicitar e justificar.

Desenhos, maquetes, protótipos, projeto de peças, desenhos explicativos de montagem... são simultâneos ou sucessivos? Quais os produtos de cada etapa?

Trabalhos parciais: serão distribuídos com base na metodologia adotada

Propor um roteiro prevendo 3 momentos de entrega com os produtos a eles relacionados.

Datas de apresentações: 16 de maio, 13 de junho, 18 de julho.

Trabalho integrado. Ao fim do semestre, cada equipe entregará, pelo menos: Identidade visual do produto, e demais peças gráficas definidas por PG1.

Documentos do processo organizados em forma de memorial e projeto detalhado..

Projeto de montagem de exposição de 10 peças variadas.

Impresso com instruções de uso e montagem

Protótipo de uma montagem mínima, em escala 1:1

a ser montado, com base nas instruções, por leigos.

Figura 1 - Plano de ações, apresentação do problema aos alunos.

Fonte: Elaborado pelos professores da disciplina.

Descrevemos como documentos do processo pedagógico descrito, o plano de aula apresentado pelos professores - tendo em vista o plano de disciplina descrito no PPP. Bem como as respostas dadas pelos alunos, pelo viés de ações projetivas, como traduzidas pelos notações de projeto e um memorial descritivo do processo. Assim, entre o Projeto Politico Pedagógico (PPP), a realização efetiva da disciplina e os resultados finais obtidos, foram gerados conhecimentos, os quais podem ser descritos a partir da análise dos documentos gerados. Tendo em vista uma abordagem do design como prática investigativa, perseguimos as redes discursivas implicadas no pensamento do projeto.

Como uma primeira mostra de documentação do processo, a Figura 1, retrata o documento gerado pelos professores, para a apresentação do problema de projeto a ser abordado na disciplina, ao longo do semestre (plano de ações), com todos os parâmetros iniciais da proposta.

Uma segunda mostragem é o relato sobre os caminhos trilhados pelos alunos para a resolução do projeto propostos, apresentado a seguir na forma de memorial descritivo dos processos.

- Descrição das estratégias de estudo aplicadas em sala de aula: 
Foram criados três grupos para o estudo das necessidades do projeto, divididos em Usuário, Material e Forma, com a intenção de levantar dados e criar um repertório antes de iniciar o projeto propriamente dito.

- Consequências:

O grupo em questão percebeu uma convergência das mesmas (necessidades) para a tratar não da forma do expositor em si, mas sim da disposição do conjunto em um espaço(...) diferentes disposições atendiam a diferentes problemáticas e conjuntos de necessidades, e que havia relevância em todas elas.

- $\quad$ Proposições - descrição do problema:

Assim nasceu a proposta de tratar não de um objeto único, mas de uma linguagem modular que permitisse a geração de várias formas, conforme a necessidade. Era necessário gerar uma linguagem unificada para o sistema, segura para os usuários e para as pessoas do ambiente, portátil, de fácil montagem $e$ estruturalmente estável. Logo se percebeu que os potencializadores dessa modularidade seriam os encaixes, que precisavam ser a culminação de todo um conjunto de necessidades vinculadas.

- $\quad$ Resolução:

A pesquisa referencial na busca de soluções de encaixe levou o grupo a procurar referências em brinquedos montáveis e, principalmente, nos modelos moleculares usados na didática da química.

- $\quad$ Possibilidades:

Em certa etapa do projeto a solução encontrada foi de hastes unidas por esferas, em alusão óbvia à representação tridimensional de estruturas moleculares. Esse momento do projeto, em especial, foi particularmente frustrante, pois a forma trabalhada se aproximava de cumprir muitas das necessidades mas era fundamentalmente incapaz de fazê-lo para todas. Foi necessário um retorno a etapas anteriores do projeto, de forma a tomar-se distância das soluções encontradas em busca de outras possibilidades.

\section{- $\quad$ Representação}

Os primeiros esboços do que se tornaria a forma final surgiram nesse momento e foram desenvolvidos. A nova proposta buscava a redução dos elementos do encaixe ao seu essencial. Partindo dessa forma, o que se sucedeu foi apenas resultado da otimização dessa solução, ajustando parâmetros para que melhor cumprissem as necessidades e retomando idéias anteriores, descartadas, de forma parcial, a exemplo do encaixe em rosca, descartado por impossibilitar o fechamento da última junção, mas livre dessa desvantagem quando aplicado somente aos encaixes no eixo vertical.

A terceira mostra documental é o relato sobre os caminhos trilhados pelos alunos para a resolução do projeto propostos, como se pode observar na figura 2 . 


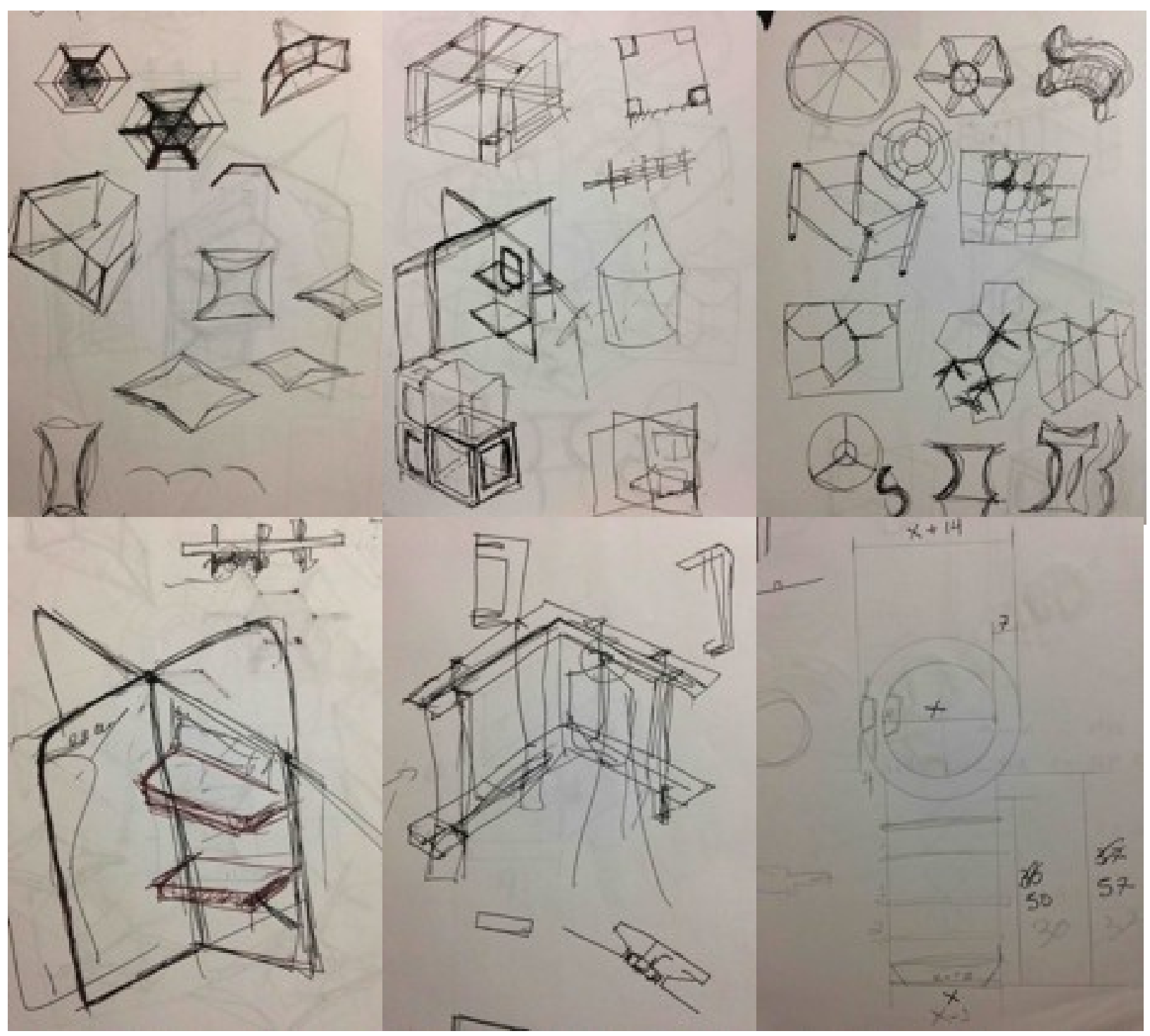

Figura 2 -Notações de projeto. Documentos de processo (esboços e desenhos). Elaborados pelos alunos.

Fonte: Elaborado pelos autores, com base na pesquisa realizada.

\section{CONCLUSÃO}

A Crítica Genética e a pesquisa-ação possibilitam uma abordagem dos processos de ensino-aprendizado a partir de uma perspectiva dialógica, bem como qualificar as informações geradas durante o desenvolvimento das disciplinas - planos de aula, notações de projeto, relatos sobre o processo, como equivalentes na construção (criação) efetiva de ações pedagógicas.

Poder compreender de que forma se operam as trocas em sala de aula, tendo em vista a constituição de uma rede discursiva, a partir da qual será construída a identidade do curso, demanda um reconhecimento das informações geradas. Essas informações se formam durante as aulas como construção coletiva tendo em vista uma dimensão criativa potencializada pelas dinâmicas pedagógicas e práticas de projeto.

Como foi demonstrado, os documentos de processo implicam os programas elaborados pelos docentes e diferentes níveis de desenvolvimento do projeto 
elaborados pelos discentes. Aqui foi apresentada uma mostra de cada agente do processo, mas serão considerados os protótipos e a apresentação final na pesquisa que comporta o conjunto dos alunos que participaram da disciplina.

Esta etapa do projeto de pesquisa do LabRep é fundamental para iniciar os processos de análise dos documentos de processo do curso e contribui para a definição dos parâmetros de análises que serão elaboradas na continuidade da pesquisa.

\section{REFERÊNCIAS}

BARBIÈR, Renè. A Pesquisa Ação. Trad. Lucie Didio. Brasília: Libel Livros, 2007.

BONSIEPE, Gui. Teoria y prática del diseño industrial: elementos para uma manualística crítica. Version Santiago Pey. Barcelona: Editorial Gustavo Gill, 1978 [1975]. Britannica Online Encyvlopedi. Disponível em http://www.britannica.com, acessado em 1 de novembro de 2013.

Design como prática de projeto. São Paulo: Blucher, 2012.

Design, Cultura e Sociedade. São Paulo: Blucher, 2011.

KRIPPENDORFF, Klaus. Design Centrado no ser humano: uma necessidade cultural. In: Estudos em Design. V.8, n. 3 (maio), 2001. Rio de Janeiro: Associação de Ensino de Design do Brasil.

LAWSON, Bryan. Como Arquitetos e Designers Pensam. Trad. Maria Beatriz Medina. São Paulo: Oficina de Textos, 2011.

LESSA, Washingnton D. Objetivos, desenvolvimento e síntese do projeto de design: consciência do método. Estudo e prática de metodologia em design nos cursos de pós-graduação. Rio de Janeiro: Novas Ideias, 2011.

MORAES, Dijon. Metaprojeto: O design do design. São Paulo: Blucher, 2010.

MUNARI, Bruno. Das coisas nascem coisas. São Paulo: Martins Fontes, 1998.

NOJIMA, Vera; ALMEIDA JR, Licinio; RIBEIRO, Adriana B. Um plano metodológico para um projeto de pesquisa em design. Estudo e prática de metodologia em design nos cursos de pós-graduação. Rio de Janeiro: Novas Ideias, 2011.

NORMAN, Donald. Design do dia a dia. Rio de Janeiro: Rocco, 2006.

SAMARA, Timothy. Evolução do Design: da teoria à prática. Porto Alegre: Bookman Editora, 2010.

TRIPP, David. Pesquisa Ação: uma Introdução Metodológica. Trad. Lélio Lourenço de Oliveira. Educação e Pesquisa, São Paulo, v. 31, n. 3, p. 443-466, set./dez. 2005.

SALLES, Cecília A. Gesto Inacabado. Processo de criação artística. São Paulo: AnnaBlumme; FAPESP, 1998.

SANTOS, B. S. Um discurso sobre as ciências. 13. Porto: Afrontamento, 2002.

SCHÖN, Donald. Educando o profissional reflexivo: um novo design para o ensino e a aprendizagem. São Paulo: Artmed, 2000. 